\title{
Vibrations of hydraulic pump and their solution
}

\author{
Lenka Dobšáková ${ }^{1, a}$, Naděžda Nováková ${ }^{1}$, Vladimír Habán ${ }^{1}$, Martin Hudec ${ }^{1}$ and Pavel Jandourek ${ }^{1}$ \\ ${ }^{1}$ Victor Kaplan Dept. of Fluid Engineering, Faculty of Mechanical Engineering, Brno University of Technology, Czech Republic
}

\begin{abstract}
The vibrations of hydraulic pump and connected pipeline system are very problematic and often hardly soluble. The high pressure pulsations of hydraulic pump with the double suction inlet are investigated. For that reason the static pressure and accelerations are measured. The numerical simulations are carried out in order to correlate computed data with experimental ones and assess the main source of vibrations. Consequently the design optimization of the inner hydraulic part of pump is done for further experimental measurements with the variable pump discharge and speed. Several optimizations were considered - guide ribs in pump suction, an optimized diffuser and modified shaft bearings. The influence of optimized designs on the pump vibrations is discussed.
\end{abstract}

\section{Introduction}

The solution of vibrations generated in the pump and piping system connected to it is often an exacting problem. But to find a source of vibrations takes a lot of time and a lot of strength. There could be many theoretical sources of vibrations. So, the discussed pump should be put to the demanding tests. [1]

An example of a solution of excess vibrations may be the case of pumps in the pumping station of a contract owner. In the pumping station high-pressure pumps with double-side inlet were used. In order to design an appropriate adjustment of the pump, which would reduce the size of vibrations; it was necessary to determine the vibration source.

\section{First measurement}

One of the pumps of the pumping station (called pump B) was subjected to a dynamic test to determine the resources of pressure pulsations. Measurements were performed on the part. Pressure pulsation and absolute vibration were measured on the bearings of the pump and the suction and the discharge piping. Transducer of pressure and transducer of acceleration were used for measuring of the required values.

The entire measuring process was continuously recorded and stored for 1 minute. The record contains four values of pressures and eight values of acceleration. The rotor and an impeller changed by the diameter were removed from the pump after the measuring and an impeller, not changed by diameter, was fitted. After balancing of the impeller and refitting further measurement was taken. When values were evaluated, options were designed that would help improve the behaviour of the whole system and not produce undesirable vibrations. [2]
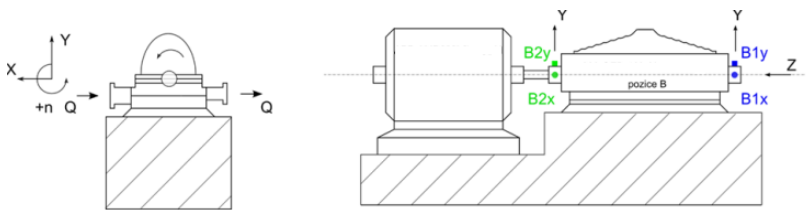

Figure 1. Representation of each measured acceleration on the pump B

\subsection{The pump parameters}

As was said before, the measured pump was highpressure, with double-side inlet. The pump includes the double-side impeller with 7 blades and diameter D2 = $460 \mathrm{~mm}$, one diffuser and one spiral case. Revolutions of the pump are $\mathrm{n}=2980 \mathrm{~min}^{-1}$. The optimum of this pump is $\mathrm{Q}_{\mathrm{opt}}=1500 \mathrm{~m}^{3} \cdot \mathrm{h}$ with head $\mathrm{H}_{\mathrm{opt}}=270 \mathrm{~m}$. Power needed for running in the optimum is $\mathrm{P}_{\mathrm{opt}}=1320 \mathrm{~kW}$.

\subsection{Evaluation of the first measurement}

Effective rate was evaluated from measured values by using accelerometers. First there was performed DFT (discrete Fourier transform). Amplitude of velocity was obtained by integrating from the calculated amplitudes of acceleration. In the frequency space it is dealt with the division of the amplitude of acceleration by angular frequency (1).

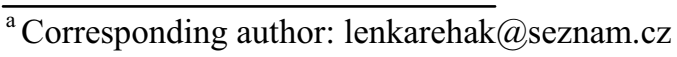




$$
v(f)=\frac{a(f)}{2 \cdot \pi \cdot f} .
$$

Effective values can be computed from equation (2):

$$
v_{e f}{ }^{2}=\frac{1}{T} \cdot \int_{0}^{T} v^{2}(t) d t
$$

Components of velocity at a frequency less than 10 $\mathrm{Hz}$ and greater than $1 \mathrm{kHz}$ are necessary to filter out to the effective velocity values that were obtained. There was performed DFT, and effective velocity values were calculated from the amplitudes of velocity in selected frequency range.

$$
v_{e f}{ }^{2}=\sum_{f=f_{1}}^{f_{2}} \frac{v^{2}(f)}{\sqrt{2}} .
$$

The equation (3) was also used for calculation of the other frequency bands than according to the standard; it is from $10 \mathrm{~Hz}$ to $1 \mathrm{kHz}$. Especially the equation (3) was used for separation of non-synchronous and synchronous vibration and for monitoring the effective contributions of the speed values in the individual frequency bands. [3]

The effective velocity values on the bearings of the pump B are shown in Figures 2 and 3. It is obvious that velocity values in the horizontal direction reach $4 \mathrm{~mm} / \mathrm{s}$ during the low flow in the impeller changed by diameter. When the impeller not changed by the diameter was used, the effective velocity values were just below $4 \mathrm{~mm} / \mathrm{s}$.

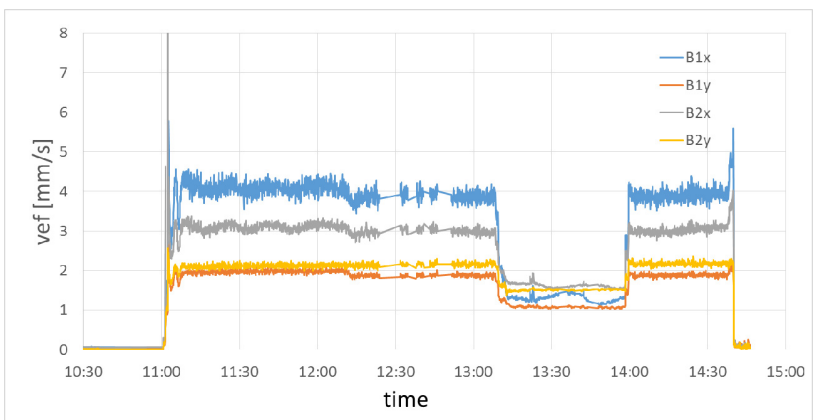

Figure 2. Effective velocity values on the bearings of the pump B. The time step is $5 \mathrm{~s}$. The impeller changed by diameter.

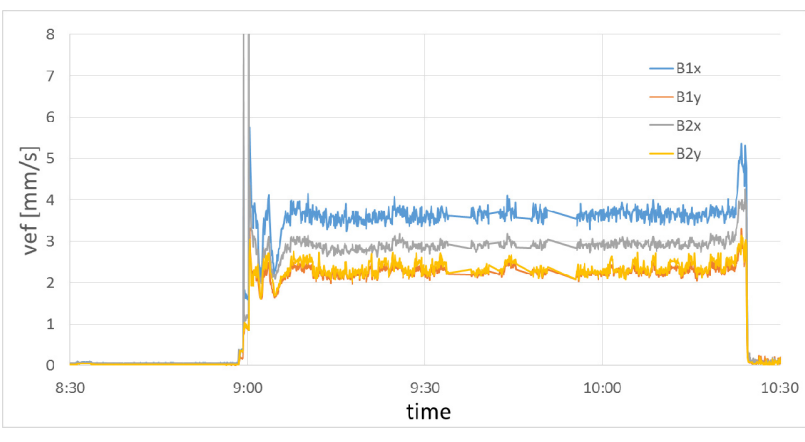

Figure 3. Effective velocity values on the bearings of the pump B. The time step is $5 \mathrm{~s}$. The impeller not changed by diameter.

Effective velocity values in different nodes of the bearing are shown on graphs in Figures 4 - 7. Values are plotted separately for $\mathrm{x}$-direction and $\mathrm{y}$-direction. They are differentiated by origin as synchronous and asynchronous. All multiples of the speed frequency \pm 1.5 $\mathrm{Hz}$ are considered to be synchronous. The component of non-synchronous vibration is evident when measuring the impeller changed by the diameter; it is in the half of the nominal flow, which is twice greater than the component of synchronous vibration. This also applies vice versa. Influence of the flow on the component of synchronous vibration is negligible, but it is very important on the component of non-synchronous vibrations. Its value varies up about 8 times by changing the flow rate from 1300 on $2350 \mathrm{~m}^{3} \cdot \mathrm{h}$.

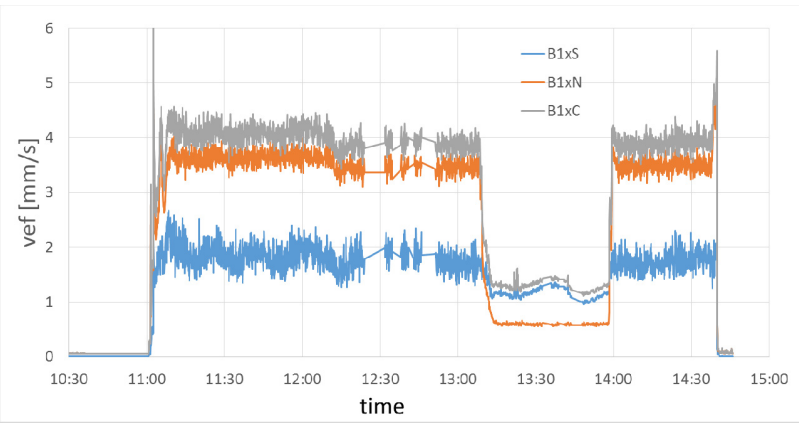

Figure 4. Effective velocity values in different nodes. Bearing $\mathrm{B} 1$ in the $\mathrm{x}$ direction for the impeller changed by diameter.

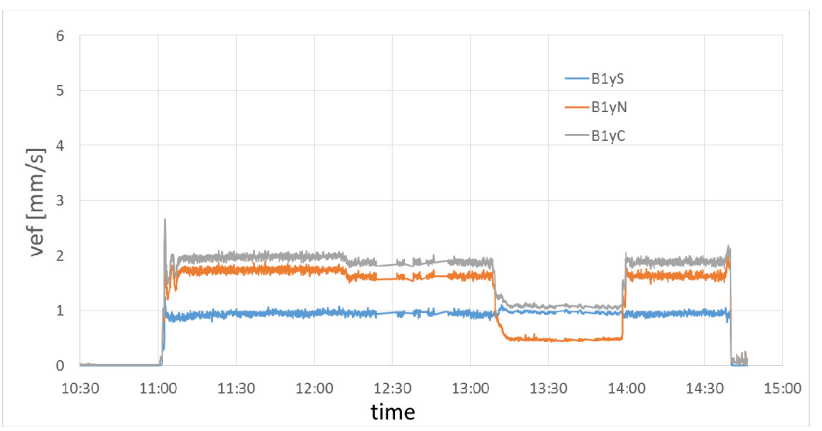

Figure 5. Effective velocity values in different nodes. Bearing $\mathrm{B} 1$ in the $\mathrm{y}$ direction for the impeller changed by diameter. 


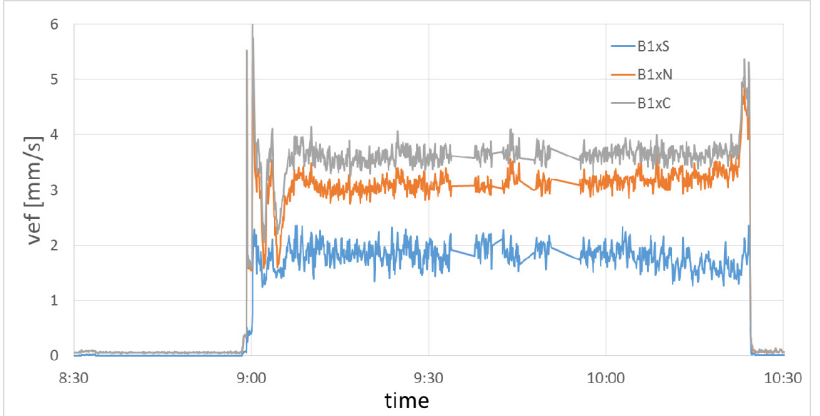

Figure 6. Effective velocity values in different nodes. Bearing $\mathrm{B} 1$ in the $\mathrm{x}$ direction for the impeller not changed by diameter.

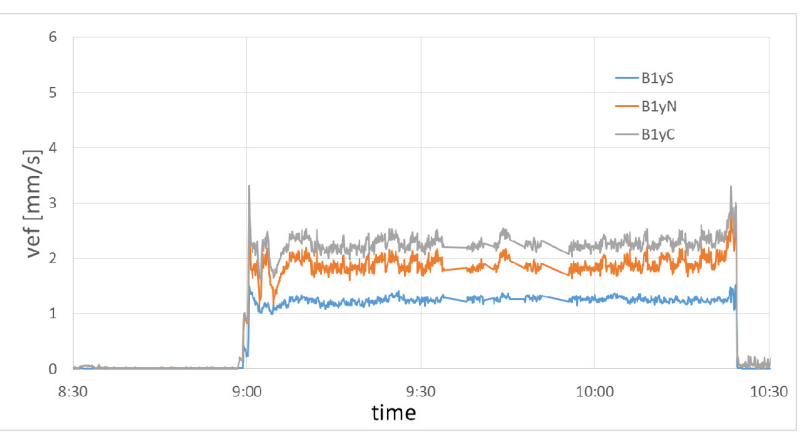

Figure 7. Effective velocity values in different nodes. Bearing $\mathrm{B} 1$ in the $\mathrm{y}$ direction for the impeller not changed by diameter.

On previous graphs the components of velocity were differentiated as synchronous and non-synchronous. Based on the results, we can say that the synchronous components of velocity have no effect on the total value of the effective rate. Therefore they are not considered in further processing and analysis will be performed only by contributions of non-synchronous components of velocity in the frequency domain.

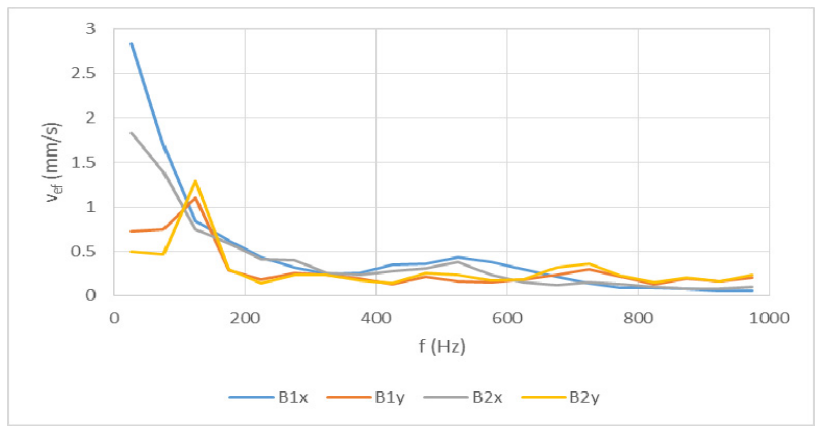

Figure 8. Effective values of velocity on the bearings of the pump B for each frequency band between multiple speeds frequencies. Synchronous components are neglected.

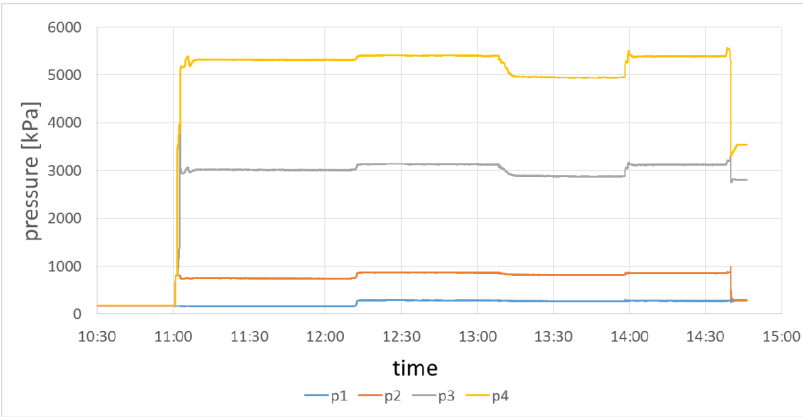

Figure 9. The time sequence of pressure measurement

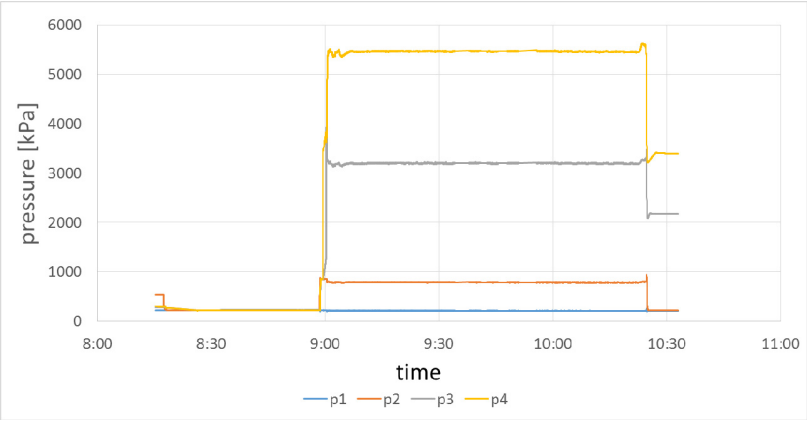

Figure 10. The time sequence of pressure measurement

Several variants have been proposed on the basis of these measured values. All these variants were measured and evaluated.

\section{Numerical simulations}

In all probability, the pump diffuser was the source of pressure pulsations. The diffuser was numerically simulated, to find out unwanted effects which were inside the diffuser. The diffuser was simulated as a $3 \mathrm{D}$ problem, because the canal width had a non-linear shape (see diagram in Figure 11, where is a diffuser with the linear change of width).

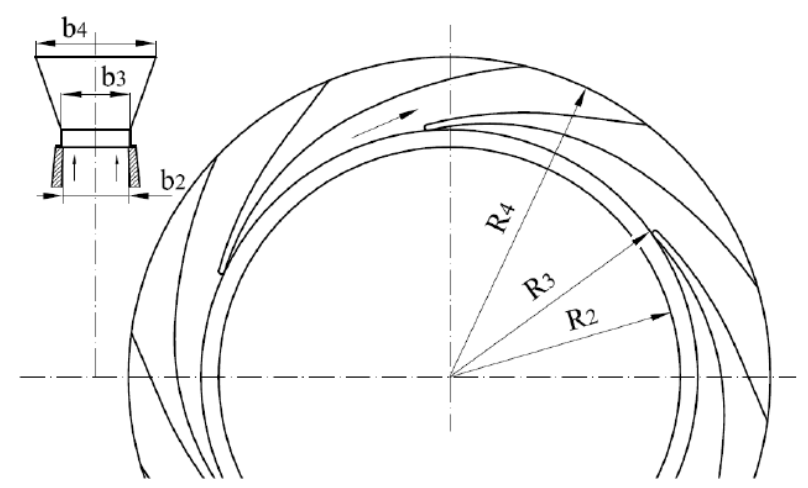

Figure 11. The schema of diffuser with the linear change of width [4].

The numerical simulation was made with the use of Ansys Fluent. Only the diffuser was simulated, without impeller and spiral case. (This could lead to a little mistake - there was set a uniform flow from an impeller.) This simplification was done for reasons of time - the 
pump was working in the pumping station and there was exerted pressure on quick resolution.

The velocity was set as a boundary condition. The velocity was determined by calculation from already measured characteristics. The impeller before the diffuser causes the fluid to enter the diffuser under specific angle. Velocity components (radial and tangential) must be set as the boundary condition on inlet. The pressure was set as the boundary condition on outlet.

The diffuser was computed for three flow rates - for the flow rate corresponding with the maximal flow rate $\mathrm{Q}_{3}=2250 \mathrm{~m}^{3} \cdot \mathrm{h}$ used on a locality, with the minimum flow rate $\mathrm{Q}_{2}=1300 \mathrm{~m}^{3} \cdot \mathrm{h}$ used on a locality and with the chosen flow rate $\mathrm{Q}_{1}=800 \mathrm{~m}^{3} \cdot \mathrm{h}$. Only three flow rates were simulated, there was no effort to do the characteristics; there was a need to find out the shape of the fluid flow inside canals. Small flow rates caused problems with vibrations, so the flow rate $\mathrm{Q}_{1}$ was chosen as a smaller one than the flow rate $\mathrm{Q}_{2}$.

Results of numerical simulation showed, that a bad fluid flow doesn't cause hydraulic shocks on leading edges of diffuser blades. Nevertheless, the diffuser contributed to vibrations of the pump. In all probability, the flow separation inside the canal could cause vibrations. Values of total velocity on the diffuser sectional view are shown in Figure 12. Apparently, the fluid flow is stabilized at the maximal used flow rate $\mathrm{Q}_{3}$. By reducing the flow rate, the fluid flow inside the canal begins tearing off. The canal at minimum used flow rate $\mathrm{Q}_{1}$ is in Figure 13, the swirling is considerable. Vortexes from the flow separation could cross in the spiral case and they could cause pressure pulsations of the pump and the connected piping system. [5] The reason for the flow separation is obvious - a rapid expansion of the canal.

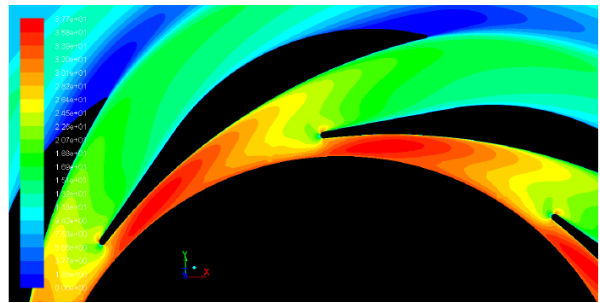

Figure 12. Values of total velocity on the diffusers sectional view - original diffuser, flow rate $\mathrm{Q}_{3}=2250 \mathrm{~m}^{3} \cdot \mathrm{h}$.

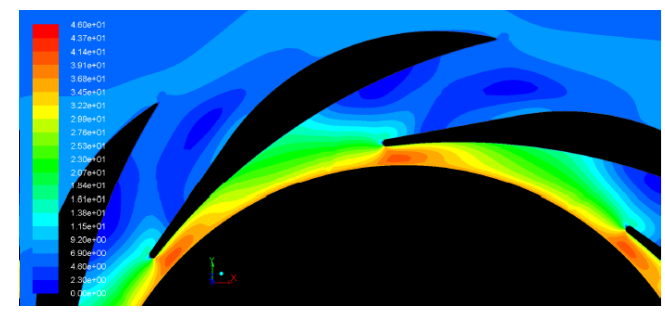

Figure 13. Values of total velocity on the diffusers sectional view - original diffuser, flow rate $\mathrm{Q}_{1}=800 \mathrm{~m}^{3} \cdot \mathrm{h}$.

Based on the simulation of the original diffuser, several simulations of adjusted diffuser were done. One of those simulations was the diffuser with half the number of diffuser blades. Another adjustment changed the width $b$ of the diffuser - the diffuser with constant width and the diffuser with the linear change of width (see Figure 11). The most suitable modification was the change of a shape of the diffuser blade (see Figure 14). The blade was adjusted to reduce the flow area of the canal, to obviate the flow separation. In comparison with the original shape of the blade (Figure 12), a significant difference is observed.

Values of total velocity in the adjusted diffuser are shown in Figure 14. Velocities in the canal are slightly increased, compared with the original diffuser, but power values needed for the working point attainment changed inconsiderable.

The adjusted diffuser was made and new measurements of pump were done.

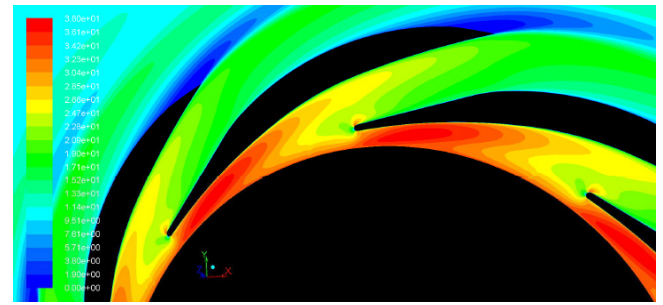

Figure 14. Values of total velocity on the diffusers sectional view - adjusted diffuser, flow rate $\mathrm{Q}_{2}=1300 \mathrm{~m}^{3} \cdot \mathrm{h}$.

\section{Solving of problems and other measurements}

The diffuser was designed for preliminary source of the vibration and it was suitably modified (see previous section). There may be even more potential sources of vibration. All these theoretical resources were addressed during the last measurements that were made to the test of the company. Measurements were carried out with several pumps of modified variants. [6]

Measured variables:

1st variant - the original pump (this variant was followed by a change of the electric motor bearings)

2nd variant - adjusting the suction inlet impeller, ribs

3rd option - adjusting the suction inlet impeller, ribs and a split diffuser used

4th variant - a new diffuser used as proposed by the University and the original suction

5th variant - the same as 4th variant, but with the new bearings on the pump

Vibrations on the pump bearings, vibrations on base of pump and vibration at the end of the tube from 2 nd variant were measured for all these measurement variations. The measurements were carried out at variable engine speeds for 9 flows for each variant. The measuring of steady state longer than 20 seconds followed after a flow setting at maximum speed of approximately $24.8 \mathrm{~Hz}$ $\left(1488 \mathrm{~min}^{-1}\right)$ and settling transient analysis. Subsequently the speeds were reduced and increased again back to the maximum value. 


\subsection{Evaluation of modified versions}

Evaluation of the measured values was performed according to the same relationship as for the first measurement. The difference was that in the evaluation only measured vibrations were considered on the bearings of the pump from a steady mode.

Furthermore there applies that disturbing frequencies are filtered off before performing the calculation by equation (3). The filtration consisted of the removal at all multiples of the amplitudes of $50 \mathrm{~Hz} \pm 1 \mathrm{~Hz}$ - there were filtered frequency $49-51 \mathrm{~Hz}, 99-101 \mathrm{~Hz}$ and so on. These disturbing frequencies were particularly noticeable on the bearing 1 in the $\mathrm{x}$-direction, and at the individual measurements varied greatly. There were also determined a rotation frequency, which was used to calculate the effective velocity of the synchronous frequency (Fig. 15) and the subsynchronous frequency (Fig. 17). Rotation frequency and all multiples of the rotation frequency plus or minus one step on a frequency, which is about $0.5 \mathrm{~Hz}$, were regarded as synchronous frequency. [7]

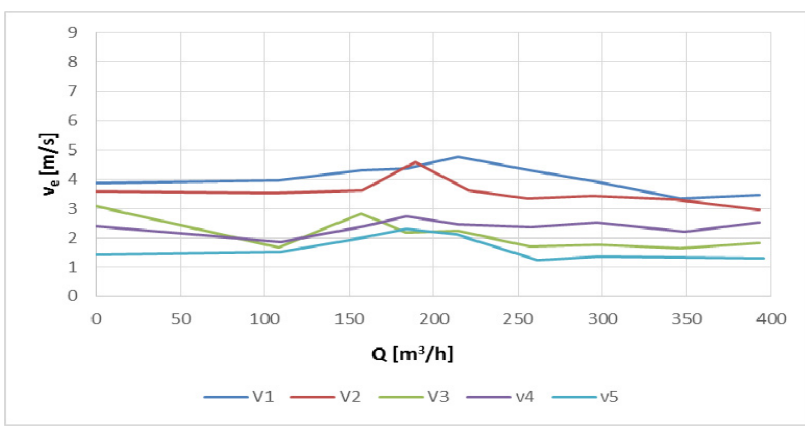

Figure 15. The bearing 1 in $\mathrm{x}$-direction, the synchronous frequency.

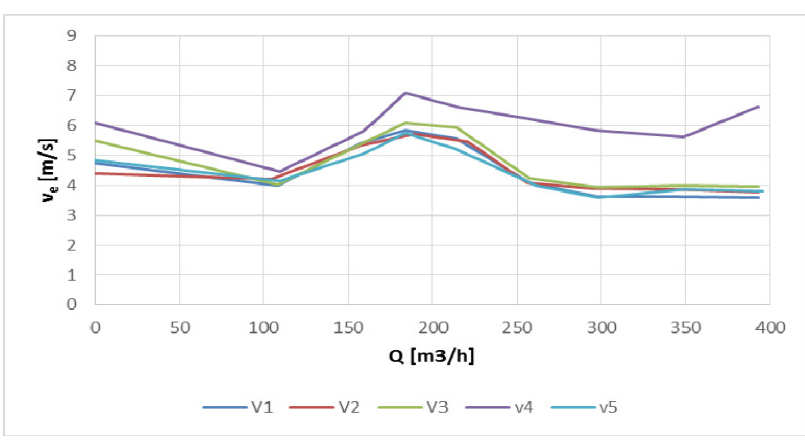

Figure 16. The bearing 1 in $\mathrm{x}$-direction, the non-synchronous frequency.

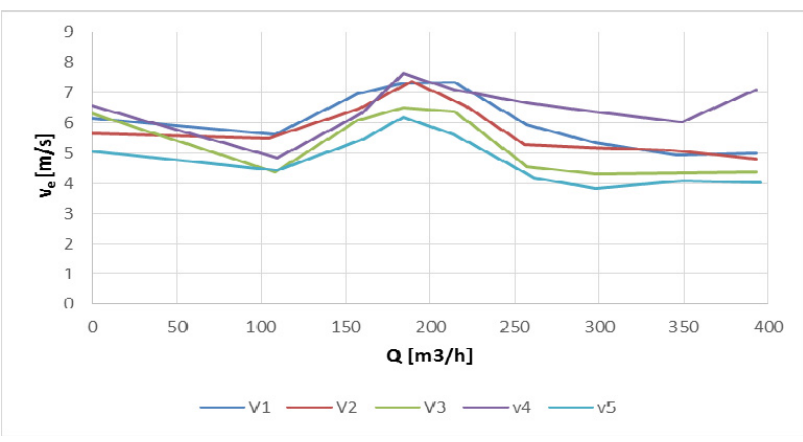

Figure 17. The bearing 1 in $x$-direction, the subsynchronous frequency.

\section{Conclusions}

The variant of the new adjusted diffuser was recommended based on the results of CFD flow modelling. Measurement on bearing 1 in the $\mathrm{x}$ direction were in most measurements burdened by significant noise at a frequency of $50 \mathrm{~Hz}$ and its multiples, even if those frequencies are filtered, probably distorting the results.

Dependence of the effective velocity on the flow can be ascertained by the following:

A comparison of 1 st and 2 nd variants shows that the impact on subsynchronous effective velocity is negligible and the impact on the synchronous effective velocity is distinct. 2nd variant came out better.

A comparison of 2 nd and 4 th variants shows that we do not resolve bearing 1 in the $\mathrm{x}$ direction because of the high noise it can be considered that the new diffuser is a slightly reduced vibration.

2nd and 3rd variants show that the divided diffusor reduced synchronous components; subsynchronous components increased slightly, overall vibration used by divided diffuser decreased. There can be traced the uniformity of vibrations for the divided diffuser at both bearings in both directions. It means that the effective velocities are the same for the one flow everywhere.

4 th and 5 th variants show that the vibration of pump slightly decreased after replacing the bearings. A significant decline was on bearing 1 in $\mathrm{x}$ direction, but there we are concerned that greater importance was the noise from the outside than bearings. The effect of bearings was on other measurements of vibration at the level of measurement accuracy.

\section{References}

1. Taneja, S.: Effect of unbalance on performance of centrigugal pump. International Journal of Scientific \& Technology Research, vol.2, issue 8, August 2013, pp.5660, ISSN 2277-8616

2. Matoušek, R.; Dobrovský, L.; Minář, P.; Mouralová, K.: A Note about Robust Stabilization of Chaotic Hénon System Using Grammatical Evolution. Advances in Intelligent Systems and Computing, 2014, roč. 2014, č. 289, s. 219-228. ISSN: 2194- 5357.

3. Dvořák, J.; Dvořáková, J.; Mouralová, K.: Application of fuzzy logic in analysis of input parameters in AWJ technology. In Mendel 2015 - 21st International 
Conference of Soft Computing - Mendel Journal Series. Mendel Journal series. 2015. s. 97-104. ISBN: 978-3319-19823-1. ISSN: 1803-3814.

4. Dobšáková, L.: Hydraulický návrh difuzoru čerpadla pro dva provozni body. Master's thesis. Brno university of technology. Brno 2012.

5. S.-S. Yang, H.-L. Liu, F.-Y. Kong, B. Xia, and L.W. Tan,: Effects of the radial gap between impeller tips and volute tongue influencing the performance and pressure pulsations of pump as turbine. Journal of Fluids Engineering, Transactions of the ASME, vol. 136, no. 5, Article ID 054501, 2014.

6. Sedlák, J.; Drábek, T.; MouralováK.; Chladil, J.; Kouřil, K.: Machining Issues of Titanium Alloys. International Journal of Metalcasting, 2015, roč. 9, č. 2, s. 41-50. ISSN: 1939- 5981.

7. Mouralová, K.; Bednář, J. Determination of significant process parameters of WEDM. Preliminary Study. In MENDEL 2013. Mendel Journal series. ISCC. Brno: BUT, 2013. s. 451-454. ISBN: 978-80-214-47554. ISSN: 1803- 3814.

8. Habán, V.: Experimentální výzkum tlakových pulsaci na čerpaci stanici. Technical report, Brno university of technology, Brno 2014.

9. Habán, V.: Výzkum tlakových pulsaci na čerpací stanici - CFD modelování rozvaděče a měření efektivních rychlostí na ložiskách na zkušebně. Technical report, Brno university of technology, Brno 2014.

\section{Acknowledgement}

Presented research was supported by centre of competence of Technology Agency of the Czech Republic TE02000232 "Rotary machines”. 